\title{
Análisis del retrato de Manuela Carmena en $A B C$ durante sus primeros cien días como alcaldesa
}

\section{Manuela Carmena's mayor portrait analysis in $A B C$ during her first one hundred days as Mayor}

\author{
Lara Carrascosa Puertas* \\ Profesora asociada en la Universidad de La Laguna \\ Miembro del Instituto Universitario de Estudios \\ de las Mujeres - ULL-IUEM \\ ORCID ID: 0000-0002-2413-2898
}

Recibido: 5/6/2019

Aceptado: $2 / 10 / 2020$

doi: https://doi.org/10.20318/femeris.2021.6141

\begin{abstract}
Resumen. Esta investigación analiza los textos periodísticos que mencionan a Manuela Carmena o están ilustrados con su imagen en el periódico ABC durante los primeros cien días de su mandato como alcaldesa (del 14 de junio al 21 de septiembre). Mediante la reconstrucción del retrato de esta mujer que hizo el rotativo se pretende poner al descubierto características y atributos de liderazgo de Manuela Carmena, así como comprobar si el género, junto con otros factores como la edad, han influido en el tratamiento mediático. La metodología está basada en el análisis de los 15 códigos que emergen de la lectura detallada de los textos 375 textos. Entre las conclusiones, encontramos que $A B C$ refuerza estereotipos de género, como el de edad o el de incumplimiento de los cánones de belleza, así como retrata a Carmena como una persona poco preparada para el cargo o con características de movimientos políticos ajenos a la democracia.

Palabras clave: Manuela Carmena; Madrid; política; género; estereotipos; sexismo.

Abstract. This research analyses journalistic texts which speak about Manuela Carmena or have her image in ABC during her first one hundred days in charge as a mayor (from 14th Juny to 21st of September). Throughout rebuilding her portrait in the newspaper, we want to discover Carmena's characteristics and leadership attributes. Likewise, we want to test if gender, along to other factors like age, has influenced in the media treatment. The methodology is based in analyzing 15 codes which emerge from reading carefully 375 texts. As some of the conclusions, we found that $\mathrm{ABC}$ reinforces gender stereotypes, like ageism or beauty canon unfulfillment. Besides, it describes Carmena as an unprepared person or with characteristic from politics movements which don't belong to democracy.

Keywords: Manuela Carmena; Madrid; politician; gender; stereotypes; sexism.
\end{abstract}

${ }^{*}$ lcarrasc@ull.edu.es 


\section{Introducción}

Las primeras mujeres alcaldesas fueron designadas durante la dictadura de Primo de Rivera, para gobernar municipios con poca población. El 8 de marzo de 1924 se promulgó el Estatuto Municipal que otorgaba el voto administrativo a las mujeres mayores de 23 años cabezas de familia, que no estuvieran sujetas a patria potestad, autoridad marital ni tutela. "Se trató de mujeres afectas al régimen de Primo de Rivera, de ideología política conservadora y defensoras del catolicismo bien por su trayectoria personal o bien por su actividad dentro de ciertas asociaciones confesionales" (Gómez-Ferrer, 2015, p.47).

La Segunda República trajo consigo la Constitución de 1931, donde se reconocía el derecho de las mujeres al sufragio activo y pasivo. Desde entonces hasta el final de la Guerra Civil, se produjo un florecimiento de las mujeres alcaldesas. De 1931 a 1939, se contabilizaron 64 alcaldesas, todas ellas en ayuntamientos de menos de 15.000 habitantes. Así, a pesar del avance en el acceso de la mujer al más alto puesto de poder en las administraciones locales, las poblaciones más grandes les seguían estando vetadas (Nielfa, 2015, p.119-122).

La dictadura del General Francisco Franco acabó con cualquier avance de empoderamiento y acceso de las féminas al poder local. Desde 1939 se abrió una brecha que se prolonga hasta 1968, año en que muchos periódicos saludan a María Teresa Ibarguchi Barrondo, alcaldesa de Ubidea (Vizcaya), como "la primera alcaldesa" de España, aseveración que más tarde tuvo que ser corregida (Nielfa, 2015).

Con la llegada de la democracia, la incorporación de la mujer a la política local continuó creciendo. En el mandato 1979-1983 hubo 104 alcaldesas (un 1,23\%) y la cifra siguió aumentando hasta que en 2011-2015 se alcanzaron las 1.355 (16,77\%). El crecimiento experimentado desde 1983 a 2015, año en Carmena fue elegida alcaldesa, fue de 17 puntos porcentuales, al pasar de 164 alcaldesas (el 2,04\% de las alcaldías) a 1550 (el 19,09\%) (Espí-Hernández, 2017).

El sustancial aumento de alcaldesas, a partir del 2007, se atribuye en parte a la aprobación de la Ley Orgánica 3/2007, de 22 de marzo, para la Igualdad Efectiva de Mujeres y Hombres. Dicha norma

exige que las candidaturas presentadas para las elecciones [...] tengan una composición equilibrada de las listas electorales. Además establece por primera vez que en el conjunto de la lista, y en todo caso en cada tramo de cinco puestos, los candidatos de uno y otro sexo no podrán estar representados en menos del 40\%. Se exceptúan los municipios e islas de menos de 5.000 habitantes [...] (Rodríguez, 2015, p.190).

No obstante, mediante un análisis de las áreas de gobierno adscritas a las mujeres que alcanzan posiciones de poder en los municipios, se puede concluir que suelen ser reducidas a aquellas consideradas más femeninas: cuidado de terceras personas (Sanidad, Servicios Sociales) o de su propia promoción (Igualdad, Mujer, Integración), mientras que los hombres se ocupan de las áreas consideradas de mayor trascendencia (Espí-Hernández, 2017).

En este sentido, Amelia Valcárcel (2012, p.187) tilda de "innegable" "la progresiva ausencia de mujeres según sea la relativa importancia simbólica de esos espacios. Y si esto 
sucede en los espacios públicos, otro tanto ocurre en los despachos privados de las grandes corporaciones". En este sentido, son varios los estudios que han abordado la escasa presencia de mujeres líderes también en el campo empresarial y las dificultades a las que se enfrentan (Mateos, 2017; Sczesney, 2003; Schein, 1996).

Manuela Carmena, nacida en Madrid en 1944, fue la primera alcaldesa electa cabeza de lista de Madrid ${ }^{1}$. Aunque su infancia y juventud se desarrolló en una España profundamente patriarcal, en la que las mujeres necesitaban permiso escrito del padre o marido para trabajar y ni si quiera tenían capacidad legal, según el ordenamiento jurídico vigente en aquel momento, para abrir una cuenta bancaria sin la aquiescencia de su padre o marido, logró, no solo realizar una carrera universitaria, sino ejercerla y desarrollarla plenamente. Está en el grupo de las primeras mujeres que accedió a la judicatura en España, junto con Josefina Trapero (1977); Milagros Calvo, María Elisabeth Huerta y Celsa Pico (las tres en 1979), y Manuela Carmena y Elisa Veiga, en 1981 (Salas, 1999). Otro de los hitos destacables de su biografía es el hecho de haber sido una de las fundadoras del despacho laboralista de Atocha que, en 1977, sufrió un atentado de la extrema derecha que acabó con la vida de varios de sus compañeros.

En cuanto a su ideología, Carmena se afilió al Partido Comunista en los años 60, cuando estaba aún estudiando en la universidad. Aunque se manifestaba "orgullosa" de pertenecer a un partido que entonces era ilegal, la exjueza no se consideró nunca "comunista" (Carmena, 2014). Respecto a sus opiniones sobre la gestión pública, entre las obligaciones que tiene el político o política que describe Carmena (2014) se encuentra la cercanía con los ciudadanos. Considera que los políticos que no son accesibles a las personas por ningún medio (carta, teléfono, email...) no están cumpliendo con su deber y aboga, no sólo por que se establezca esta comunicación, sino por que respondan a las demandas de la ciudadanía de diálogo con sus representantes. En ese sentido, defiende "una democracia más directa, más distinta", donde "los partidos no tienen sitio" (Torres, 2015, 56-57).

Carmena asumió el cargo de alcaldesa de Madrid el 13 de junio de 2015, como cabeza de la formación Ahora Madrid, derivada de varias corrientes dentro del partido político de ámbito nacional Podemos, pasando, así, a convertirse en uno de los focos de atención de los medios de comunicación.

\subsection{Justificación del interés del tema y del objeto de estudio}

La cifra de mujeres líderes en el mundo aún está por debajo de la de hombres (Ryan et al, 2016; Meldelberg, 2016; O’Brien, 2016; Espí-Hernández, 2017). En concreto, en las elecciones españolas de 2015, 1.550 mujeres fueron elegidas como alcaldesas de otros tantos municipios. Esta cifra representa solo el 19,09\% de las alcaldías de España, según cifras recogidas por el Instituto de la Mujer (2015).

\footnotetext{
${ }^{1}$ La primera alcaldesa de Madrid fue Ana Botella, pero recordemos que iba en segunda posición en la lista del Partido Popular (PP), encabezada por Alberto Ruiz de Gallardón. Cuando éste abandonó el cargo para convertirse en ministro de Justicia, ella ascendió directamente a alcaldesa.
} 
Las féminas pueden acceder a cualquier profesión en los países democráticos, pero en la práctica la presencia de mujeres va menguando según se asciende en la escala de poder de cada ámbito. Es lo que se ha denominado "techo de cristal", con el que se designa "todo el conjunto de prácticas y maniobras que dan como resultado que las mujeres sean desestimadas por los sistemas de cooptación" (Valcárcel, 2012, p.98) o, también, esas barreras invisibles con las que se encuentran para avanzar en sus carreras profesionales y que no están relacionadas con sus méritos laborales (Chisholm-Burns, 2017). “Consequenly, even wealthy, powerful women are disadvantaged by gender status beliefs compared to wealthy, powerful male peers" (Ridgeway, 2001, p.638-639).

En el campo de la política, la presión social y cultural no predispone a las mujeres a participar ni a ocupar puestos de relevancia, más bien al contrario, suelen quedar relegadas a áreas consideradas femeninas (Méndez, 2001). Esta presión es definida por algunos autores en clave de creencias o estereotipos de género que llevan a pensar que las mujeres están menos cualificadas para el liderazgo, lo que, a su vez, mina la autoestima de las mujeres y puede impedirlas actuar de forma eficiente en campos donde es más importante para las féminas entrar, debido a que han estado históricamente dominados por hombres (Eagly, 2016).

Además, las mujeres que ocupan diferentes puestos en las esferas gubernamentales están expuestas a lo que se ha denominado "violencia política", cuyas formas "más usuales identificadas sería el examen de la vida privada y la descalificación de las capacidades de las mujeres afectadas" (Soriano, 2020, p.148).

Por su parte, los medios de comunicación seleccionan los acontecimientos que pasan a ser noticias en función de criterios como la novedad, el valor informativo y la curiosidad, entre otros. No obstante, Galtung y Ruge (citados por McQuail, 1975, p.330) afirmaron que cualquier hecho tenía "más probabilidad" de convertirse en noticia cuanto más se ajustara a determinados criterios organizacionales o ideológicos, que se refieren principalmente a valores arraigados en la sociedad occidental. De esta forma, los medios en general y periódicos en particular tienden a enviar mensajes que propician el mantenimiento del establishment. Lippmann (1922, p.93) advertía que los periódicos son el reflejo de la opinión pública, pero, al mismo tiempo, proveían de estereotipos a la sociedad, que definía como "una imagen ordenada y más o menos coherente del mundo" en el que "las personas y las cosas ocupan un lugar inequívoco y su comportamiento responde a lo que esperamos de ellos". Los estereotipos, así, fijan modelos rígidos de masculinidad y femineidad y forman parte del mundo de lo simbólico (Plaza, 2007, p.24).

El género, por otro lado, tiene mucho que ver con la construcción de los relatos informativos y los estereotipos. El concepto de género ha sido definido como

un sistema normativo (dicta las normas de conducta de mujeres y hombres) y coercitivo (reprime las conductas que no se ajustan a las normas). Asigna al hombre y a la mujer roles y funciones diferenciados, así como distintos espacios, actividades, identidades, derechos y deberes. De esta forma, el género se ocupa de construir la diferencia sexual como desigualdad social: en razón de los roles y las características asignadas a cada sexo, el sistema 
de género atribuye a las mujeres una posición subordinada y a los hombres una de poder sobre los principales recursos (Bengoechea, 2015, p.10).

Bordieu (2015, pp.120-121) explica, en el mismo sentido, que

al quedar excluidas del universo de las cosas serias, de los asuntos políticos, y sobre todo económicos: las mujeres han permanecido durante mucho tiempo encerradas en el universo doméstico y en las actividades asociadas a la reproducción biológica y social del linaje; actividades (maternales ante todo) que, aunque aparentemente reconocidas y a veces ritualmente celebradas, sólo lo son en la medida en que permanecen subordinadas a las actividades de producción, las únicas en recibir una auténtica sanción económica y social, y ordenadas de acuerdo con los intereses maternales y simbólicos del linaje, es decir, de los hombres.

En la misma línea, Simone de Beauvoir (1949: 853-854) consideraba que la implicación de las mujeres en su profesión "depende del contexto que constituye la forma global de su vida" [...].

Cuando aborda su vida de adulta, no tiene tras ella el mismo pasado que un niño; la sociedad no la considera con los mismos ojos; el universo se le presenta desde una perspectiva diferente. El hecho de ser mujer plantea actualmente a un ser humano autónomo problemas singulares.

La prensa sería la encargada de divulgar y mantener gran parte de esos estereotipos y funciones diferenciadas en función del género, mediante los hombres y mujeres concretos que escriben en ella. Estos eligen lo que es noticia, lo encuadran ${ }^{2}$ y seleccionan las palabras, el discurso, mediante el cual llega a las audiencias. En este sentido, encontramos que las mujeres apenas aparecen como protagonistas de los hechos que se consideran noticiables; "su presencia no se ha incrementado proporcionalmente a su incorporación a los espacios públicos, económicos, políticos, culturales...; cuando aparecen, suelen ser representadas como víctimas pasivas y pacientes, en situaciones anecdóticas o como objeto de ironía", por ello, la mayor presencia de mujeres en la prensa generalista "se registra en las páginas de anuncios breves de contactos y relax" (Moreno et al., 2007, pp.17-18).

Las diferencias estereotípicas de género tienen su reflejo en la construcción del discurso de los medios de comunicación. La resistencia psicológica de la sociedad española a aceptar a las mujeres en igualdad de condiciones o capacidad en determinados puestos de poder va desde la realidad a la representación simbólica en el discurso y, de vuelta, al reforzamiento de estereotipos y prejuicios en la sociedad.

Un ejemplo se encuentra en el Libro de estilo del $A B C$, en el apartado de "Cuestiones gramaticales y de estilo", en su subepígrafe denominado “Género” (Vigara, 2001, pp.83-87).

\footnotetext{
2 "El framing o encuadre consiste en un sutil proceso de selección que realizan los medios de ciertos aspectos de un tema, que son presentados como más importantes y que, por tanto, enfatizan causas particulares de los fenómenos” (D’Adamo et al., 2007, p.136).
} 
En esta parte del manual de uso interno del medio destinado a resolver dudas lingüísticas y unificar el estilo y el lenguaje del rotativo, hay una entrada dedicada a "títulos y profesiones desempeñados por mujeres", en la que se rechaza la feminización de determinados términos, con el argumento de que "suena mal".

Títulos y profesiones desempeñados por mujeres

a) En la última edición del diccionario (21. $\left.{ }^{a}, 1992\right)$, la Real Academia ha recogido (también) en femenino la inmensa mayoría de los cargos, títulos y profesiones desempeñados por mujeres. No obstante, algunos de estos femeninos no sólo no están todavía bien asentados en el uso, sino que "suenan" mal a los usuarios, que en ocasiones los rechazan abiertamente. Entre ellos jueza, edila, concejala, bedela y tenienta, que en $\mathrm{ABC}$ se mantendrán con género común: (el/la) juez, edil, concejal, bedel, teniente.

b) (La) árbitro. Como nombre de profesión, se usa todavía muy poco en femenino, pues la mujer comienza ahora a incorporarse profesionalmente a esta actividad. Aunque el diccionario académico recoge en su tercera aceptación dos formas: Árbitro, tra. M. y f. Persona que en algunas competiciones deportivas de agilidad y destreza cuida de la aplicación del reglamento,

Recomendamos utilizar, si fuera necesario, esta combinación (la árbitro, una/alguna/ ninguna árbitro, los árbitros, etc.), que parece, por el momento, la que menos choca con el uso "intuitivo" de la mayoría de los hablantes (Vigara, 2001, p.86-87).

\section{Objetivos y metodología}

Los objetivos generales de esta investigación son (OG1) descubrir las características y atributos del liderazgo de Manuela Carmena recogidos en el periódico $A B C$ durante los primeros cien días de mandato, y (OG2) comprobar si el género de Manuela Carmena, junto con otros factores (la edad, el no militar en una formación política y haber desarrollado una profesión de élite, entre otras) ha contribuido a un tratamiento diferencial en $A B C$.

Para la consecución de estos objetivos generales, se han planteado objetivos específicos y técnicos, como se especifica en la Tabla 1

Tabla 1. Objetivos generales, específicos y técnicos. Elaboración propia.

\begin{tabular}{|l|l|l|}
\hline \multicolumn{1}{|c|}{ Objetivo general } & \multicolumn{1}{c|}{ Objetivos específicos } & \multicolumn{1}{c|}{ Objetivos técnicos } \\
\hline $\begin{array}{l}\text { OG1. Descubrir las ca- } \\
\text { racterísticas y atributos } \\
\text { de liderazgo de Manuela } \\
\text { Carmena en } A B C\end{array}$ & $\begin{array}{l}\text { OE1. Analizar el discurso } \\
\text { impreso a la búsqueda de } \\
\text { patrones de género que } \\
\text { impliquen desigualdad o } \\
\text { subordinación. }\end{array}$ & $\begin{array}{l}\text { Realizar un conteo de los textos y fotografías sobre Ma- } \\
\text { nuela Carmena, categorizando los mismos en "opinión" e } \\
\text { "información". Hallar expresiones sexistas, que estereoti- } \\
\text { pen, en los textos que se refieren a la alcaldesa, realizando, } \\
\text { asimismo, una categorización de las distintas estereotipias } \\
\text { aparecidas. Ponderar cuál ha sido el tratamiento general } \\
\text { que le ha dado. Crear categorías/códigos que reflejen atri- } \\
\text { butos o caracterizaciones que emanan del discurso del me- } \\
\text { dio. Examinar las informaciones en busca de expresiones } \\
\text { subjetivas, más propias de los textos de opinión. }\end{array}$ \\
\hline
\end{tabular}




\begin{tabular}{|l|l|l|}
\hline \multicolumn{1}{|c|}{ Objetivo general } & \multicolumn{1}{|c|}{ Objetivos específicos } & \multicolumn{1}{c|}{ Objetivos técnicos } \\
\hline $\begin{array}{l}\text { OE2. Indagar en la } \\
\text { construcción del } \\
\text { discurso informativo } \\
\text { sobre Manuela Carmena } \\
\text { para hallar patrones } \\
\text { sexistas que se repitan, } \\
\text { independientemente del } \\
\text { medio informativo del que } \\
\text { se trate. }\end{array}$ & $\begin{array}{l}\text { Realizar un conteo de los textos y fotografías sobre Manuela } \\
\text { Carmena, categorizando los mismos en "opinión" e "infor- } \\
\text { mación". Hallar expresiones sexistas, que estereotipen, en } \\
\text { los textos que se refieren a la alcaldesa, realizando, asimis- } \\
\text { mo, una categorización de las distintas estereotipias apa- } \\
\text { recidas. Ponderar cuál ha sido el tratamiento general que } \\
\text { le ha dado el medio. Crear categorías/códigos que reflejen } \\
\text { atributos o caracterizaciones que emanan del discurso del } \\
\text { medio. Examinar las informaciones en busca de expresio- } \\
\text { nes subjetivas, más propias de los textos de opinión. }\end{array}$ \\
\hline $\begin{array}{l}\text { OG2. Comprobar si el } \\
\text { género de Manuela } \\
\text { Carmena, junto con } \\
\text { otros factores (la } \\
\text { edad, no pertenecer a } \\
\text { un partido político y } \\
\text { haber desarrollado una } \\
\text { profesión de élite) ha } \\
\text { contribuido al tratamiento } \\
\text { diferencial de } A B C\end{array}$ & $\begin{array}{l}\text { OE3. Localizar campañas } \\
\text { de desprestigio y analizar } \\
\text { cuáles son las categorías } \\
\text { de ideas sobre las que } \\
\text { giran (prejuicios sobre la } \\
\text { edad, sobre su capacidad } \\
\text { profesional, maneras de } \\
\text { vestir, entre otros). OG1. }\end{array}$ & $\begin{array}{l}\text { Realizar un conteo de los textos y fotografías sobre Ma- } \\
\text { nuela Carmena, categorizando los mismos en "opinión" e } \\
\text { "información". Hallar expresiones sexistas, que estereoti- } \\
\text { pen, en los textos que se refieren a la alcaldesa, realizando, } \\
\text { asimismo, una categorización de las distintas estereotipias } \\
\text { aparecidas. Ponderar cuál ha sido el tratamiento general } \\
\text { que le ha dado } A B C \text {. Crear categorías/códigos que reflejen } \\
\text { atributos o caracterizaciones que emanan del discurso del } \\
\text { medio. Examinar las informaciones en busca de expresio- } \\
\text { nes subjetivas, más propias de los textos de opinión. }\end{array}$ \\
\hline
\end{tabular}

Tabla 2. Categorías, códigos y definiciones en la investigación sobre los cien primeros días de mandato de Manuela Carmena. Elaboración propia.

\begin{tabular}{|c|c|c|}
\hline Categoría & Código & Definición \\
\hline $\begin{array}{l}\text { Aspectos } \\
\text { formales }\end{array}$ & Estilo directo & $\begin{array}{l}\text { Cuando las declaraciones de Carmena se ponen en estilo directo. Bengoechea seña- } \\
\text { la que un caso de estudio fundamental, por la "enorme capacidad de divulgación" } \\
\text { es "la concesión de voz de los medios: a quién se le otorga voz, a quién se silencia } \\
\text { y cómo se informa de la voz a la que se permite hablar". Menciona una investiga- } \\
\text { ción realizada en The Times, The Guardian y The Independent (Caldas-Coulthard, } \\
\text { 1995), que concluyó que la prensa concede un papel muy reducido a la voz fe- } \\
\text { menina (sólo un } 14 \% \text { de las declaraciones habían sido hechas por mujeres). Mati- } \\
\text { za que en muchos casos los portavoces de las organizaciones son hombres. "Pero } \\
\text { incluso en los casos en los que las mujeres son figuras políticas o sociales con re- } \\
\text { levancia, los diarios tienden a minorar sus declaraciones al concederles menos } \\
\text { espacio físico en el periódico, a glosarlas (en lugar de citarlas mediante estilo di- } \\
\text { recto entrecomillando sus palabras) y a utilizar diferentes verbos declarativos (de- } \\
\text { cir, afirmar, declarar...) para ellos y para ellas cuando se quiere introducir la voz". } \\
\text { En el caso de España, se realizó un estudio centrado en los diarios El País, El Mundo y } \\
\text { La Vanguardia, en el que sea analizaron } 434 \text { páginas y } 524 \text { noticias de una semana del } \\
\text { año } 200 \text {. En este caso, el estilo indirecto se usaba con mayor frecuencia cuando se ci- } \\
\text { taban las palabras femeninas, y las citas de estas eran apreciablemente más cortas que } \\
\text { las citas de palabras expresadas por varones (Bengoechea, 2001). "La cita indirecta } \\
\text { suele ser más indicativa de la perspectiva adoptada por el periódico, ya que se presta } \\
\text { a una interpretación de las palabras pronunciadas, a las que no se concede autoridad } \\
\text { suficiente para ser reproducidas literalmente" (Bengoechea, 2015, p.108-109). }\end{array}$ \\
\hline $\begin{array}{l}\text { Aspectos } \\
\text { formales }\end{array}$ & Estilo indirecto & $\begin{array}{l}\text { Cuando las palabras de Carmena se ponen en estilo indirecto. También se contabiliza } \\
\text { en estilo indirecto cuando se mencionan dos o alguna palabra más entrecomilladas, } \\
\text { evitando así el estilo directo. }\end{array}$ \\
\hline $\begin{array}{l}\text { Aspectos } \\
\text { formales }\end{array}$ & $\begin{array}{l}\text { Fotografía } \\
\text { de Manuela } \\
\text { Carmena }\end{array}$ & Cuantifica las imágenes de Manuela Carmena. \\
\hline
\end{tabular}




\begin{tabular}{|c|c|c|}
\hline Categoría & Código & Definición \\
\hline $\begin{array}{l}\text { Aspectos } \\
\text { formales }\end{array}$ & Portada & Cuando se menciona Carmena o se utiliza su imagen en la portada del periódico. \\
\hline $\begin{array}{l}\text { Aspectos } \\
\text { formales }\end{array}$ & $\begin{array}{l}\text { Género } \\
\text { periodístico }\end{array}$ & Indexa el género periodístico concreto al que pertenece el texto. \\
\hline $\begin{array}{l}\text { Aspectos } \\
\text { semánticos }\end{array}$ & Genitivo & $\begin{array}{l}\text { Cuando se utiliza algún tipo de posesivo para mencionar a los concejales del Ayunta- } \\
\text { miento de Madrid: Los Carmena, los ediles carmenistas, el concejal de Carmena, etc. } \\
\text { También cuando se colectiviza a Carmena (hablando por ejemplo de Los Carmena). } \\
\text { La intención última de este código es descubrir un patrón que trata de colocar a Car- } \\
\text { mena como responsable última de comportamientos de otras personas. }\end{array}$ \\
\hline $\begin{array}{l}\text { Aspectos } \\
\text { semánticos }\end{array}$ & Exjuez/exjueza & $\begin{array}{l}\text { Contabiliza por un lado las veces que se refieren a Manuela Carmena como exjuez y, } \\
\text { por otro, las veces que se usa la forma "jueza". }\end{array}$ \\
\hline $\begin{array}{l}\text { Aspectos } \\
\text { semánticos }\end{array}$ & Ironía & $\begin{array}{l}\text { Cuando se utiliza este recurso lingüístico para hablar de Carmena, independiente de } \\
\text { la forma en que se ponga práctica (adjetivos, construcciones lingüísticas fijas, este- } \\
\text { reotipos....). }\end{array}$ \\
\hline $\begin{array}{l}\text { Aspectos } \\
\text { semánticos }\end{array}$ & Liderazgo & $\begin{array}{l}\text { Hace referencia a las caracterizaciones del liderazgo de Manuela Carmena, en refe- } \\
\text { rencia a la percepción disminuida de su competencia profesional en virtud a los pre- } \\
\text { juicios de género existentes. }\end{array}$ \\
\hline $\begin{array}{l}\text { Aspectos } \\
\text { semánticos }\end{array}$ & Populismo & $\begin{array}{l}\text { Indexa todas las citas que contienen referencias al populismo de Manuela Carmena } \\
\text { o su equipo. }\end{array}$ \\
\hline $\begin{array}{l}\text { Aspectos } \\
\text { semánticos }\end{array}$ & Radicalismo & $\begin{array}{l}\text { Hace referencia a todas las citas que identifican a Manuela Carmena o su gobierno } \\
\text { como extremistas o radicales (se ha dividido este código en diversos tipos de radica- } \\
\text { lismo para intentar precisar más el retrato que se pretende mostrar). }\end{array}$ \\
\hline $\begin{array}{l}\text { Aspectos } \\
\text { semánticos }\end{array}$ & $\begin{array}{l}\text { Referencias } \\
\text { a la edad } \\
\text { peyorativas }\end{array}$ & Recoge cualquier referencia peyorativa a la edad de Manuela Carmena. \\
\hline $\begin{array}{l}\text { Aspectos } \\
\text { semánticos }\end{array}$ & $\begin{array}{l}\text { Referencias a } \\
\text { la edad }\end{array}$ & Recoge cualquier referencia a la edad de Manuela Carmena. \\
\hline $\begin{array}{l}\text { Aspectos } \\
\text { semánticos }\end{array}$ & Sexismo & $\begin{array}{l}\text { Acotamos aquí sexismo como cualquier intento de menospreciar la preparación, la } \\
\text { trayectoria o la capacidad de Carmena en contraposición, principalmente, con una } \\
\text { figura masculina, o cuando se alcanzan grados altos de menosprecio. Asimismo, tam- } \\
\text { bién seleccionamos las citas en las que se identifica a Carmena con un esterotipo típi- } \\
\text { camente femenino, "sexista". "Sexism is difficult to define in contemporary research, } \\
\text { because not everyone agrees about exactly what constitutes sexism. Some argue that } \\
\text { sexism is any language use which seems to represent women in a negative way; some } \\
\text { consider it as negative generalizations based on stereotypes about men and women } \\
\text { (Vetterling-Braggins, 1981, citado por Mills, 2011, p.144). "Sexism is also a position } \\
\text { which has some institutional support (albeit to different degrees) in a contemporary } \\
\text { societies. It is not a view of women that the speaker or writer has invented, but rather } \\
\text { just a body of ideas and phrases which others have expressed and which are presented } \\
\text { as 'common sense'. Sexism has an agentless feel to it, and because of this, it achieves } \\
\text { authority unless it is challenged" (Mills \& Mulany, 2011, p.145). }\end{array}$ \\
\hline $\begin{array}{l}\text { Aspectos } \\
\text { semánticos }\end{array}$ & Venezuela & $\begin{array}{l}\text { Indexa todas las citas que hacen referencia o relacionan a Manuela Carmena o su } \\
\text { equipo con Venezuela o el chavismo. }\end{array}$ \\
\hline
\end{tabular}

Para aproximarnos a nuestros objetivos, hicimos un previo vaciado del periódico de todos los textos que mencionaban o estaban ilustrados con una imagen de Manuela Carmena, publicados entre el 14 de junio y el 21 de septiembre de 2015 . A estos 375 textos (368 unidades de género periodístico y siete portadas) se les aplicó una metodología basada en la aplicación de análisis de contenido. Se ha utilizado el software Atlas.ti y se 
han dividido los códigos emanados del análisis en dos categorías que recogen los aspectos formales y los aspectos semánticos. Los códigos creados tienen un valor determinado dentro de un sistema de categorías concreto (Trinidad et al., 2006). Los códigos, a su vez, han emergido del microanálisis de los textos y su agrupación, conforme a sus propiedades más sobresalientes, buscando similitudes y diferencias, desde el enfoque de la Teoría Fundamentada (Strauss \& Corbin, 2002).

En total, se han aplicado un total de 15 códigos, que se han definido previamente y se han exportado desde Atlas.ti a un libro de códigos con la finalidad de poder replicar esta investigación en otras cabeceras y llevar a cabo una posterior investigación comparativa sobre los distintos retratos que han realizado los medios de Manuela Carmena en esta ventana temporal.

Los códigos que se han aplicado en esta investigación son los que se citan en la Tabla 2.

\section{Resultados de la investigación y discusión}

Para presentar los resultados de esta investigación se han agrupado los códigos aplicados en las categorías de aspectos formales, que son aquellos que afectan solo a la forma en la que se presenta el mensaje, y aspectos semánticos, que se refieren a la utilización de diversos recursos lingüísticos que connotan el mensaje escrito.

\subsection{Aspectos formales}

\subsubsection{Estilo indirecto y estilo directo}

Estos códigos agrupan las declaraciones que se recogen de Manuela Carmena en estilo directo e indirecto. En este sentido, Bengoechea señala que un caso de estudio fundamental, por la "enorme capacidad de divulgación" es "la concesión de voz de los medios: a quién se le otorga voz, a quién se silencia y cómo se informa de la voz a la que se permite hablar". Menciona una investigación realizada en The Times, The Guardian y The Independent (Caldas-Coulthard, 1995), que concluyó que la prensa concede un papel muy reducido a la voz femenina (sólo un 14\% de las declaraciones habían sido hechas por mujeres), incluso en los casos en los que las mujeres son figuras políticas o sociales con relevancia.

A pesar de que la diferencia entre uno y otro código no parece significativa (94 citas en estilo directo y 100 en estilo indirecto), hay que subrayar la relevante diferencia existente, a favor del estilo indirecto, hasta la décimo tercera semana, coincidiendo con la participación de Carmena en el foro $A B C$, evento organizado y financiado por el periódico.

$A B C$ ha hablado mucho sobre Carmena, pero en pocas ocasiones le ha dado la oportunidad de expresarse por ella misma, con sus propias palabras. Siempre ha necesitado un filtro, una ayuda, una referencia a ella por parte de otra persona. El periódico explica lo que quiere decir la alcaldesa como si careciera de voz propia. 
Figura 1. Comparativa de la distribución entre citas en estilo directo y en estilo indirecto de Manuela Carmena en el ABC. Elaboración propia.

\section{Comparativa de estilos por semana en $A B C$ (junio a septiembre 2015)}

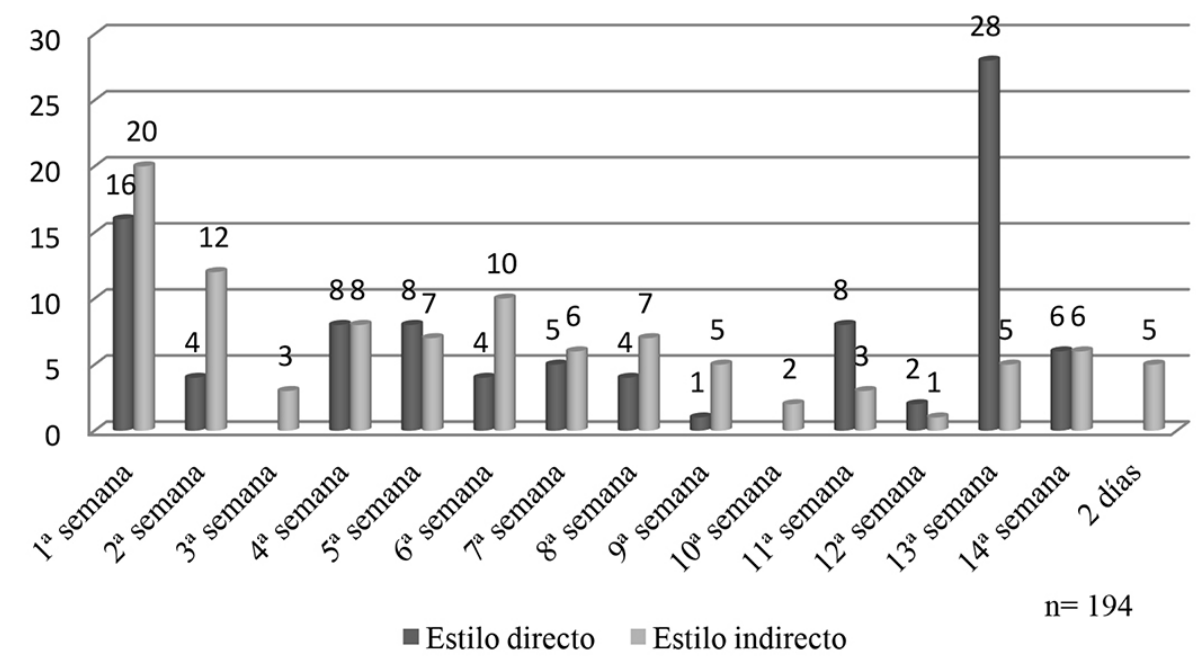

Respecto a la densidad de estos códigos en las piezas de opinión y de información, como es previsible, hay más citas en información que en opinión (estilo directo, 84 y 10; estilo indirecto, 89 y 11 , respectivamente).

Llama también la atención que Carmena solo haya escrito un artículo de opinión (su propia voz, sus propias palabras) en $A B C$ en 100 días de análisis, mientras que en el mismo periodo Ana Botella, exalcaldesa de Madrid, publicó tres ${ }^{3}$ y Esperanza Aguirre, adversaria política y cabeza del Partido Popular (PP) en la oposición, uno ${ }^{4}$. El artículo de Aguirre, además, tenía un contenido centrado en la política municipal, dado que hacía balance de los primeros 100 días Manuela Carmena en la alcaldía de Madrid. Sin embargo, el artículo de Carmena se refería a una columnista de $A B C$ que leía en su juventud, por lo que no aborda en el texto nada que tenga que ver con la política municipal. Encontramos, así, un claro contraste, además de en la cantidad, en el contenido de las cuatro piezas firmadas por políticas del PP y la única firmada por Carmena.

\subsubsection{Imágenes de Manuela Carmena}

Se publicaron un total de 88 fotografías, imágenes o dibujos de Manuela Carmena en 100 días. La mayoría de ellas (67) en textos informativos y el resto en opinativos (21). Cuatro veces la fotografía de Manuela Carmena fue portada del $A B C$. Llama la atención que

\footnotetext{
${ }^{3}$ Botella, A. (16 de junio de 2015). La vivienda en Madrid, al alcance de todos. $A B C$, 70; Botella, A. (22 de julio de 2015). Madrid: la ayuda y las palabras. $A B C, 28$, y Botella, A. (15 de septiembre de 2015), Auditorías. $A B C$, 29. Solo el último forma parte de esta investigación porque menciona explícitamente a Carmena.

${ }^{4}$ Aguirre, E. (21 de septiembre de 2015). Su objetivo, el ascenso de Pablo Iglesias. $A B C, 89$.
} 
se utilice la fotografía de Manuela Carmena en textos en los que ni si quiera habla de ella (ni en estilo directo ni indirecto). Un ejemplo es "El caso Alfon desenmascara a actores y políticos antisistema" ${ }^{2}$.

\subsubsection{Los géneros periodísticos}

Esta categoría pretende identificar el tipo de textos que predominan en piezas donde se menciona a Carmena o se ilustran con su fotografía. Como es habitual en investigaciones en las que se realizan análisis de contenido de medios de comunicación, hay mayor volumen de textos informativos, no obstante en este caso la cifra es muy cercana a los textos de opinión: un 57\% de textos informativos y un $43 \%$ de opinión.

Figura 2. Distribución de los textos sobre Carmena en el ABC, según su género periodístico. Elaboración propia.

\section{Género periodístico de los textos sobre Carmena en el ABC (jun-sept 2015)}

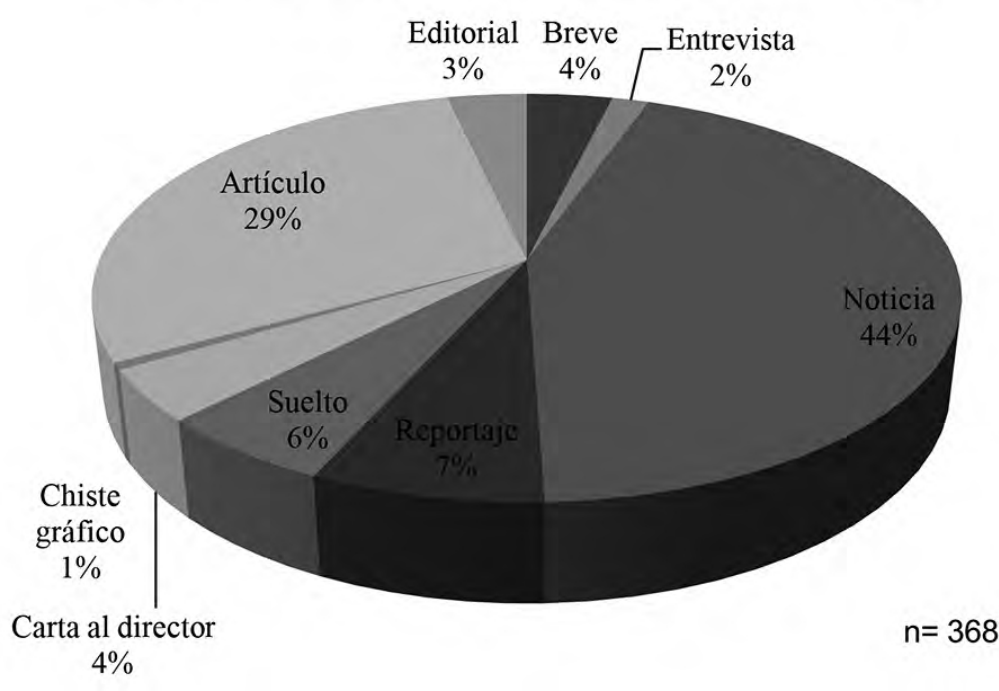

Las entrevistas, por ejemplo, son siempre a personas que no forman parte del Gobierno Municipal, salvo dos: una al concejal de Economía y otra a Luis Cueto, jefe de Gabinete. La única entrevista que se recoge de la alcaldesa (y en estilo indirecto) es una que le realizó la agencia de noticias Europa Press en las primeras semanas de mandato.

\subsubsection{Portadas}

Se han contabilizado cinco portadas con la foto de Carmena (solo una connotaciones positivas o neutras, la que recogía su participación en el Foro $A B C$ ) y dos más que tratan de

${ }^{5}$ Rivas, T.G. (29 de junio de 2015). El caso Alfon desenmascara a actores y políticos antisistema. $A B C, 18$. 
Carmena aunque no aparece su foto sino la de un comedor vacío y la imagen de la antigua sede de Correos (hoy ayuntamiento), respectivamente.

Los titulares de primera son de tipo interpretativo y no se ajustan a la deontológica separación entre géneros informativos y de opinión.

- "España consuma su giro radical a la izquierda" (14 de junio de 2015)

- "Ay, Carmena" (16 de junio de 2015).

- "Carmena duplicó los desahucios en un año como juez decana" (10 de julio de 2015).

- "Carmena no dice la verdad" (11 de julio de 2015).

- "La izquierda fracasa en su intento de instrumentalizar el hambre" (30 de julio de 2015).

- "No tengan miedo, sé que necesitamos a las empresas" (9 de septiembre de 2015).

- "El PP recuperaría Madrid tras solo 90 días de gobierno populista" (13 de septiembre de 2015).

\subsection{Aspectos semánticos}

Hay 9 códigos que se han agrupado en esta categoría, debido a su potencial influencia en la configuración de significados sobre Manuela Carmena. Algunos directamente mediante la utilización de determinados epítetos o conceptos. Otros, indirectamente, configurando un retrato del liderazgo de Manuela Carmena o de determinadas características de su vida o personalidad.

\subsubsection{Exjuez}

Este código se considera de relevancia por dos motivos fundamentales: porque recuerda al lector que la persona que ha sido elegida alcaldesa desarrolló una profesión de élite, y porque en el Libro de Estilo de $A B C$ se recoge específicamente que se debe de escribir "exjuez" (Vigara, 2001, pp.86-87), manteniendo así una postura conservadora y lejana del lenguaje inclusivo o igualitario que tiende a visibilizar la mujer.

En el caso de Carmena, sin embargo, en más de una ocasión se desliza "jueza”, sobre todo en artículos de opinión, lo que nos ofrece la visión de que $A B C$ es un periódico conservador, que impone una nomenclatura desde su propio libro de estilo, pero que muchos de sus columnistas sí han aceptado la feminización del vocablo juez y no respetan ni usan la fórmula "la juez".

No obstante todo esto, hay un total de 52 citas recogidas como "la juez" o "la exjuez", de las que 42 están en textos informativos y 9 en textos de opinión; frente a la construcción "la jueza" que son 26 en total, 12 en información y 14 en opinión. Por consiguiente, el lenguaje rígido y no inclusivo al referirse a Carmena predomina claramente. Parece relevante, de cualquier modo, que se introduzca la expresión "jueza" en textos informati- 
Figura 3. Comparativa entre la utilización de las fórmulas "la juez" y "jueza" en referencia a Carmena en el ABC. Elaboración propia.

\section{La juez vs la jueza Carmena (jun-sept 2015)}

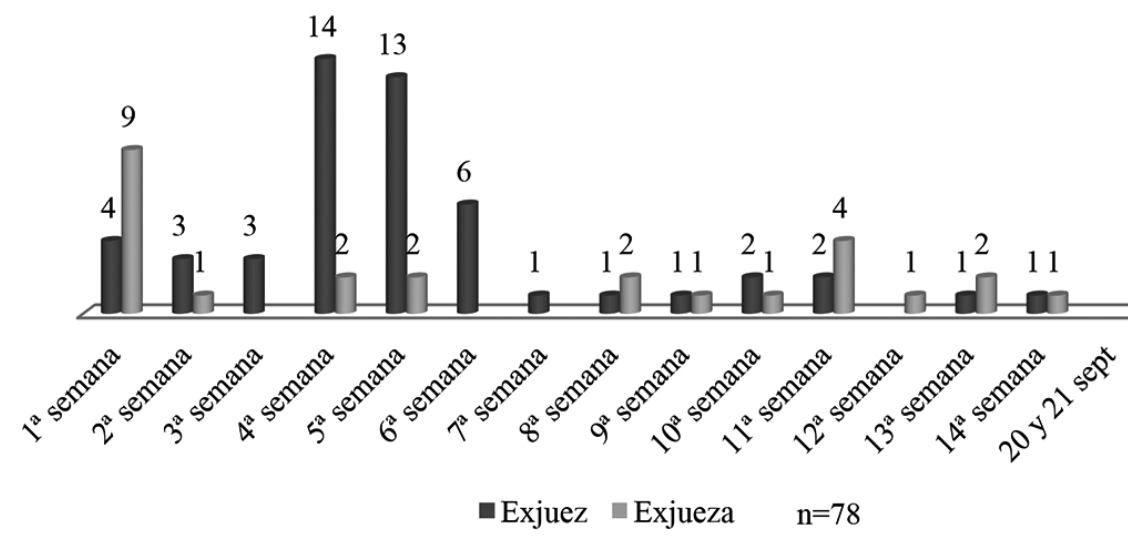

vos, incluso cuando antes se había referido a ella como "la juez", y que sea una tendencia general aceptada entre los articulistas de opinión hablar de "la jueza"6.

En los textos informativos se suele utilizar exjuez o exjueza (o sus sinónimos jurista o magistrada) como forma de evitar repeticiones. No tiene un contenido semántico más explícito que este, aun reconociendo que la repetición favorece la percepción general de Carmena como una mujer de valía, con una profesión de élite. Sin embargo, esta percepción queda amortiguada por el uso cualitativo que se realiza en los artículos de opinión, en los que con frecuencia se pone en entredicho su valía o criterio profesional. Valga de ejemplo una columna titulada “¡Y era jueza!”, en la que el autor dice?:

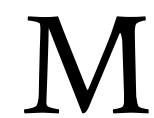

anuela Carmena es un personaje simpático: una señora septuagenaria con elevado sentido de la justicia poética, que se paseaba en bici por Malasaña, regentaba una tienda de filosofía solidaria, se movilizó contra Franco desde el PCE y fue una jueza más bien estrafalaria. Una señora mayor de curioso perfil, un poco dispersa, que flipa instalada en su utopía marxiana y quijotesca. Un personaje simpático, sí pero solo en el contexto de una comedieta de situación castiza, tipo “Aida” a la vera del Luisma, tomándose un cortao en el bar de Mauricio y desbarrando de política, no para gestionar el Ayuntamientode la capital de España con un presupuesto de 4.000 millones de euros.

Es sintomático que en la primera semana de mandato de Carmena, así como la cuarta y la quinta, sean en las que hay más menciones a su condición de exjueza. Como hemos

\footnotetext{
${ }^{6}$ La contabilización total alcanza las 92 citas totales, porque también se han incluido otras fórmulas como magistrada o jurista, pero estas no se contabilizan en este análisis lingüístico de la utilización de la forma femenina de la profesión de juez.

7 "Manuela Carmena es un personaje simpático: una señora septuagenaria con elevado sentido de la justicia poética, que se paseaba en bici por Malasaña, regentaba una tienda de filosofía solidaria, se movilizó contra Franco desde el PCE y fue una jueza más bien estrafalaria. Una señora mayor de curioso perfil, un poco dispersa, que flipa instalada en su utopía marxiana y quijotesca. Un personaje simpático, sí, pero solo en el contexto de una comedieta de situación castiza, tipo "Aída", a la vera del Luisma, tomándose un cortao en el bar de Mauricio y desbarrando de política, no para gestionar el Ayuntamiento de la capital de España, con un prespuesto de 4.000 millones de euros", en Ventoso, L. (18 de junio de 2015). ¡Y era jueza! ABC, 14.
} 
visto, en los textos de opinión en la primera semana para intentar desacreditarla, en la cuarta para atacar su supuesta doble moral en las ejecuciones de desahucios, y en la quinta todas las citas están en textos de información porque continúan el tema del repunte de los lanzamientos hipotecarios cuando Carmena era jueza.

\subsubsection{Genitivo}

Este código se creó para identificar las numerosas referencias que se hacía a Carmena como responsable última de todas las personas que forman parte de su gobierno o su equipo. Se codifica como "genitivo" todo texto que aplica un posesivo sobre la alcaldesa. Aunque pueda parecer un mero giro estilístico, es altamente inusual y tiende a la personalización del equipo en una sola persona, al margen, incluso, de partidos políticos.

Las consecuencias semánticas de este código en la construcción de significados sobre Manuela Carmena son la centralización de todos los problemas o conflictos en la figura de la alcaldesa, la tendencia generalizada a responsabilizar a Carmena de todo lo que ocurre o han hecho en el pasado sus concejales, el desgaste de la alcaldesa, mediante la atribución de cualquier asunto, acción o declaración de cualquier persona de su equipo de gobierno, y el subrayado del posible nepotismo de la alcaldesa.

En total se codificaron 158 citas, de las que 113 estaban en textos de información y 45 en textos de opinión, lo que indica que esta tendencia a centralizar la responsabilidad de todo en Carmena se plasma principalmente desde los textos informativos. Valgan dos ejemplos de titulares informativos para ilustrar esta tendencia: ${ }^{8 / 9}$

\section{El edil de Carmena solo deja el área de Cultura y sigue siendo concejal}

\section{Un desnudo en una capilla acorrala a la portavoz de Carmena}

\subsubsection{Ironía}

Este código mide toda intención de ridiculizar a la alcaldesa o a su gobierno, que, como hemos visto en el código denominado "genitivo", tiende a convertirse en un ataque directo contra Carmena. Este código se encuentra, asimismo, dentro de una tendencia general e histórica a mofarse de las mujeres que ocupan puestos de poder o destacan en alguna rama profesional considerada masculina ${ }^{10}$.

\footnotetext{
${ }^{8}$ Rivas, T.G. y Medialdea, S. (16 de junio de 2015). El edil de Carmena solo deja el área de Cultura y seguirá siendo concejal. $A B C$, pp. 16-17.

${ }^{9}$ Rivas, T.G. (18 de junio de 2015). Un desnudo acorrala a la portavoz de Carmena. $A B C, 25$.

${ }^{10}$ En este apartado también podemos destacar, como ejemplo, las masivas campañas antisufragistas, donde se afeaba o ridiculizaba a las mujeres.
} 
Se han registrado un total de 116 citas de este código, de las que 107 están en textos de opinión y 9 en textos informativos. La "burla fina y disimulada", como la define el DRAE, debería estar solo presente en los textos de opinión, puesto que los de información tendrían que estar exentos de esa carga de opinión. No son muchos los casos, pero hablar de las "ocurrencias" de Carmena o de la "primera verbena -y no castiza- de Manuela Carmena", entre otros ejemplos, implica un posicionamiento ideológico del periodista que solo debería informar.

\subsubsection{Liderazgo}

Este código se utiliza para localizar e indexar las características atribuidas al liderazgo político de Manuela Carmena. Su utilización ha sido muy amplia porque la caracterización del liderazgo de Carmena es constante. Son 694 citas en total, de las que 465 están en textos informativos y 229 en textos de opinión. En cuanto a la caracterización positiva del liderazgo de Manuela Carmena, mediante características como la escucha y la reflexión, se limita a 38 citas.

El liderazgo de Carmena está siempre en entredicho y está caracterizado por atributos como que suelta lo primero que se le ocurre (tanto en el caso de las cooperativas de madres como en su intervención en el Foro $A B C$ ), que sus concejales no le hacen caso (caso de la tasa turística), que no conoce los nombres de sus concejales (dicho en un artículo de opinión), que dice que no es de Podemos, pero que se presentó como cabeza de lista de una de sus marcas blancas (Ahora Madrid), que está ahí solo para que Pablo Iglesias gane las elecciones; que piensa lo mismo que Pablo Iglesias, pero después; que quiere que los delincuentes salgan de la cárcel; que es hipócrita (dice que quiere frenar los desahucios, pero multiplicó los lanzamientos cuando era decana; dice que usa el transporte público, pero coge algún taxi o coche oficial también; dice que se va a bajar el sueldo, pero no lo hace); que tiene un alto concepto de sí misma; que está en contra del empresario Wanda; que se inventa los niños malnutridos que hay en Madrid; que se va a promocionar un libro a Argentina; que es comunista, y que quiere silenciar a los medios de comunicación a través de su web de la verdad, entre otras muchas cosas que se escribieron sobre ella que sería imposible reproducir en este texto.

Carmena, no obstante, resultó ser la política considerada más cercana en una encuesta encargada por $\mathrm{ABC}$, pero este dato casi pasa desapercibido, al no destacarse en ningún sumario, lead o titular de despiece. A pesar de las críticas de $A B C$, Carmena sí que es percibida como una persona independiente (aunque fuera la cabeza de lista de Ahora Madrid) y cercana, un valor en alza dado el desapego entre la ciudadanía y los líderes políticos propiciado por la multiplicación de casos de corrupción.

Por otro lado, son significativos los verbos en voz activa utilizados cuando Carmena es el sujeto de la oración en los titulares de las informaciones, entre los que podríamos destacar "fulmina", "tira a la basura" o "gasta". 


\subsubsection{Populismo}

La definición de populismo, según el DRAE, es "tendencia política que pretende atraerse a las clases populares". El diccionario especifica que se usa en sentido despectivo. Este código se creó para contabilizar las constantes referencias a Carmena o su gobierno como populista. También se han indexado las referencias a "demagogia" en este código, por considerarlos términos del mismo campo semántico.

En total, se han hallado 97 citas, de las que 36 están en textos de información y 61 en textos de opinión. Tildar el gobierno municipal de populista es una afirmación altamente subjetiva, por lo que todas las menciones deberían ir en textos de opinión, salvo las que sean declaraciones de un concejal de la oposición. Pero los cintillos, titulares y demás elementos informativos hablan por sí solos de esta tendencia más interpretativa que informativa: ${ }^{11 / 12}$

\section{El populismo irrumpe en las grandes capitales con el aval decisivo del PSOE}

\section{El populismo desestabiliza el sector turístico español}

Por otro lado, se observa una tendencia decreciente en este tipo de menciones que repunta solo en la décimo cuarta semana, con motivo principalmente de la publicación de los resultados de la encuesta de $A B C$ cuyos resultados afirman que si se repitieran las elecciones la alcaldía volvería a manos del Partido Popular.

Figura 4. Distribución de las citas sobre "populismo" en referencia a Manuela Carmena en el ABC. Elaboración propia.

$$
\begin{gathered}
\text { "Populismo" de Carmena en } A B C \\
\text { (jun-sept 2015) }
\end{gathered}
$$

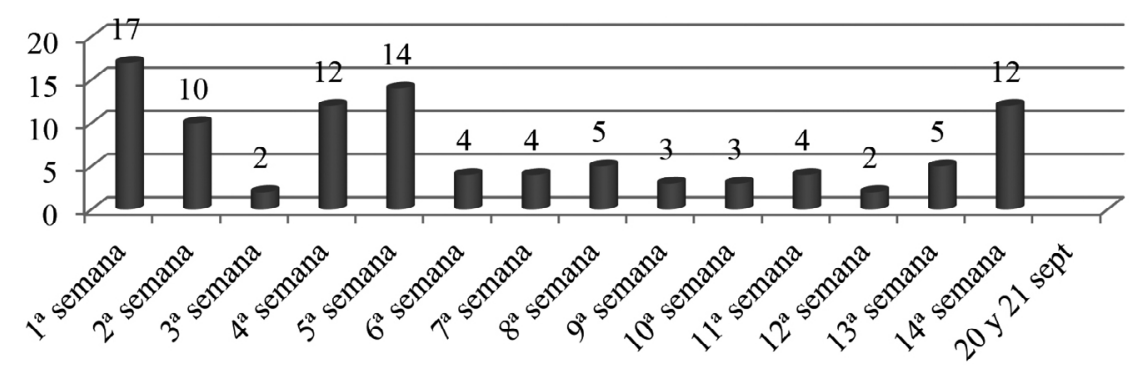

${ }^{11}$ Calleja, M. y Sanz, G. (14 de junio de 2015). El populismo irrumpe en las grandes capitales con el aval decisivo del PSOE. $A B C$, pp. 20-22. 57.

${ }^{12}$ Calvo, E. y Rodríguez, A. (12 de julio de 2015). El populismo desestabiliza el sector turístico español. $A B C$, pp.56- 
El mayor número de menciones de este código se concentra en la primera semana, con motivo de su investidura. La quinta semana se sitúa en segunda posición, con la argumentación de que Carmena, en campaña electoral, sostenía que quería acabar con los desahucios, pero, al mismo tiempo, los había facilitado cuando era jueza decana; por desestabilizar supuestamente el sector turístico en Madrid con el anuncio de una tasa y por la web Versión Original. La cuarta semana se sitúa en tercer lugar por los desahucios, por la revisión del callejero franquista y por dar voz a la oposición que se expresa en esos términos en citas en estilo directo.

\subsubsection{Radicalismo}

Este código se creó para indexar todas aquellas menciones en las que se identifica a Carmena o a sus concejales como radicales. Dada la variedad de radicalismos que mencionan, se dividió el código en radicalismo, radicalismo extrema izquierda, radicalismo abertzale, radicalismo okupa y radicalismo república y radicalismo anticonstitucional.

El radicalismo, según el DRAE, es "la doctrina que propugna la reforma total de todo orden político, científico, moral y religioso". Radical, como adjetivo o sustantivo, es "el partidario de reformas extremas".

Se han indexado un total de 51 citas de "radicalismo", 25 en información y 26 en opinión. Se observa una tendencia muy pronunciada a calificar como radicales a Carmena o su equipo en las dos primeras semanas de mandato, que se atenúa hasta casi desaparecer al final de los cien primeros días.

Figura 5. Distribución de la caracterización de Manuela Carmena como radical en el ABC. Elaboración propia.

\section{"Radicalismo" de Carmena en $A B C$ (jun-sept 2015)}

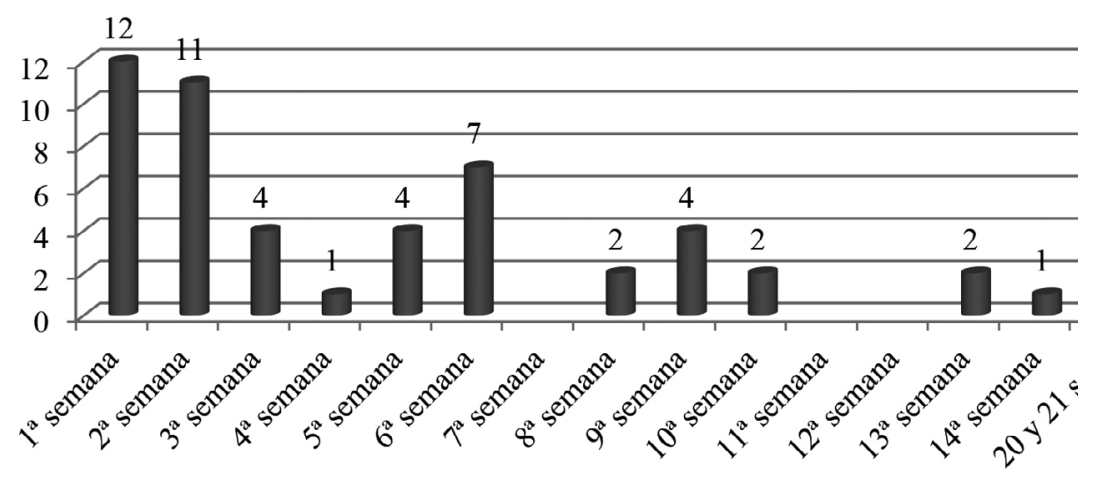

Por otro lado, el código "radicalismo abertzale" indexa todas las menciones o comparaciones de Manuela Carmena y su equipo con ETA, el terrorismo o el entorno abertzale. Se registraron solo nueve citas, de las que 7 estaban en textos informativos y dos en textos de opinión. Estas menciones se concentran en las tres primeras semanas de mandato de 
Manuela Carmena (cuatro, tres y dos, respectivamente), desapareciendo después de los textos de forma absoluta. Se puede decir que en el imaginario colectivo no ha calado esta caracterización, puesto que los abertzales son un grupo muy específico, delimitado en determinados espacios de España, y los concejales y alcaldesa de Ahora Madrid no encajaban de forma indubitable en este perfil.

Por su parte, "radicalismo anticonstitucional" indexa todas las menciones a Manuela Carmena o su equipo como individuos de ideas anticonstitucionales, antidemocráticas y antisistema. Aunque no son específicamente sinónimos, hemos agrupado todas estas menciones por considerar que comparten el mismo núcleo semántico: se refieren a personas que no están conformes con el orden establecido en España como país democrático. Este código no tiene mucho enraizamiento: un total de 13 citas, de las que 8 están en textos informativos y 5 en textos de opinión. No obstante, "radicalismo extrema izquierda" es el código que más enraizamiento tiene de todos "radicalismos. Se ha utilizado para indexar las menciones a Manuela Carmena o a su equipo como personas de ideología ultraizquierdistas, comunistas, o simpatizantes de personas o grupos de extrema izquierda. Se contabilizaron un total de 104 menciones, de las que 66 están en textos de opinión y 38 en textos informativos. Como en otras subdivisiones del código "radicalismo", se produce una explosión de estos términos en la primera semana de mandato de Manuela Carmena, que desciende después y queda como un goteo de entre dos y diez menciones por semana.

Hay que matizar que Manuela Carmena militó en el Partido Comunista durante la dictadura franquista, aunque en este análisis solo se hallaron dos menciones a este hecho en la décimo primera semana. Además, ella misma mencionó su condición de "no comunista"13 en el foro $A B C$ (semana décimo tercera), lo que influye en el número de menciones, aunque no de forma importante (fueron solo 6 menciones en esa semana).

Algunos ejemplos de este código en información: ${ }^{14 / 15}$

\section{Concejales de la izquierda radical acatan la Constitución por imperativo legal y al grito de "sí se puede"}

\section{Los alcaldes de la izquierda radical ven prioritaria la memoria histórica}

En la misma línea que el anterior, radicalismo okupas indexa todas las referencias en las que se relaciona a la alcaldesa o a su equipo como simpatizantes de colectivos o grupos okupas. Se detectaron un total de 91 citas, de las que 71 están en textos informativos y

\footnotetext{
${ }^{13}$ En varias ocasiones, Carmena asegura que ella nunca se sintió comunista, pero que en ese momento histórico parecía la forma de trabajar por la llegada de la democracia a España.

${ }^{14}$ Subtítulo de la información de Calleja, M. y Sanz, G. El populismo irrumpe en las grandes ciudades con el apoyo decisivo del PSOE. $A B C$, pp.20-22.

${ }^{15}$ Castro, M.R. y Delegaciones ABC. Los alcaldes de la izquierda radical ven prioritaria la memoria histórica. $A B C$, pp.18-19.
} 
20 en textos de opinión. El motivo principal de la prevalencia de estas citas en información es que $A B C$ toma una serie de hechos noticiosos y aprovecha para relacionarlos de alguna manera con la alcaldesa o su equipo. A veces de una forma más o menos inocua, como cuando menciona que la alcaldesa está muy preocupada por la situación del Colegio Mayor San Juan Evangelista, pero en la mayoría de las ocasiones existe una connotación hostil. Un ejemplo claro es la nueva ocupación tras el desalojo del Patio Maravillas, donde se menciona que varios de los concejales de Ahora Madrid han sido simpatizantes o han estado integrados en este movimiento. Tras el compromiso de Carmena de buscarles una ubicación, se realiza un artículo extenso sobre inmuebles ocupados (es otro tipo de ocupación, derivada de la crisis económica) y se la acusa de crear un efecto llamada (aunque en el texto se ve claramente que las fechas de las ocupaciones coinciden con de años de gobierno del Partido Popular y con el recrudecimiento de la situación económica global). Incluso en el caso del reducido grupo de jóvenes que "okupan" la calle, se menciona en varias ocasiones que Carmena les saludó y se comprometió a reunirse con ellos (al menos en 100 días, no hay constancia escrita de que lo hiciera).

Una primera interpretación de tanta incidencia en este código es la intencionalidad manifiesta del periódico por retratar a Carmena y a su grupo de gobierno como personas que provienen de o simpatizan con grupos que no respetan la propiedad privada, que es un concepto que forma parte de los principios editoriales y los valores tradicionales defendidos y postulados por $A B C$. De hecho, la novena semana, que es en la que se registran mayor número de citas, coincide con el reportaje mencionado sobre los edificios ocupados en Madrid, y los jóvenes acampados en Cibeles. Algunos ejemplos en información de esa semana: ${ }^{16 / 17 / 18}$

\title{
Unos 300 "okupas" se hacen fuertes en una treintena de edificios de Madrid
}

\section{Mapa de la “okupación” Indignación vecinal}

\author{
Interior: Hay que actuar ante \\ el auge "okupa" y cumplir la ley"
}

El código radicalismo república, por su parte, indexa las menciones que se hacen a La República en relación con Manuela Carmena o su equipo de Gobierno. Son muy pocas: solo ocho citas, de las que cinco están en textos informativos y tres en de opinión. En la primera semana, los textos informativos se concentran principalmente en la investidura,

\footnotetext{
${ }^{16}$ (11 de agosto de 2015). Unos 300 "okupas" se hacen fuertes en una treintena de edificios de Madrid. $A B C, 2$.

${ }^{17}$ Cintillo de Álvarez, M.J. (11 de agosto de 2015). Tensión en Pueblo Nuevo por la toma de un bloque de pisos por radicales. $A B C, 50$

${ }^{18}$ Delgado, A. (12 de agosto de 2015). Interior: "Hay que actuar ante el auge «okupa» y cumplir la ley". $A B C, 51$
} 
en la que se dice que había gente con banderas republicanas. Uno de ellos es una referencia al comportamiento de un agente miembro de Ahora Madrid que después fue objeto de una rectificación en el periódico por ofrecer datos que no eran veraces. ${ }^{19}$

\section{Manuela Carmena y Ada Colau prometen en el cargo de alcaldesas entre banderas republicanas y gritos de "sí se puede"}

\subsubsection{Referencias a la edad de Manuela Carmena}

Existen un total de 10 referencias a la edad de Manuela Carmena, tres en información y siete en opinión. Este código indexa las que parecen a simple vista inocuas, que no van cargadas de ningún sentido peyorativo. No obstante, la edad es un aspecto que funciona de forma diferente en mujeres y hombres, de forma que cumplir años en mujeres es considerado 'no bello' dado que las mujeres consiguen más poder con el tiempo (Wolf, 2002).

Los textos informativos que hacen referencia a la edad de la alcaldesa corresponden al perfil básico que se hizo de ella en su investidura y a una referencia de Esperanza Aguirre a una conversación con Manuela Carmena. Las menciones de opinión, salvo una en que es la propia Carmena quien habla de su edad, tienen una carga negativa: con la edad que tiene, cómo hace esto.

Más numerosas y significativas son las referencias peyorativas a la edad de Manuela Carmena. Este código indexa, específicamente, solo las referencias negativas a la edad de

Figura 6. Comparativa entre las referencias a la edad de Carmena neutras y negativas en el ABC. Elaboración propia.

Referencias a la edad de Carmena en $A B C$ (jun-sept 2015)

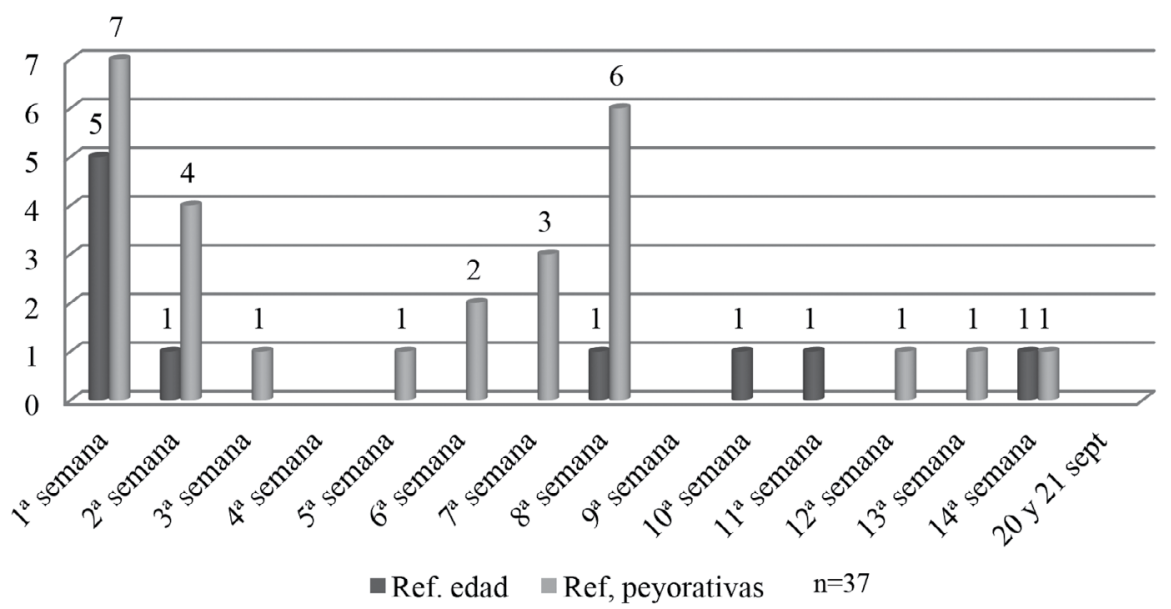

${ }^{19}$ Subtítulo de (14 de junio de 2015). España consuma su giro raAdical a la izquierda. $A B C, 1$. 
Manuela Carmena. En especial cuando se refieren a ella como "abuela". Estas citas casi triplican a las que se refieren a su edad sin más. Son un total de 27 citas y todas están en textos de opinión. De hecho, el columnista Ignacio Ruiz-Quintano, que escribe la columna "Visto y no visto" de la contraportada, tiene una marcada tendencia a llamar "abuela" a Manuela Carmena. 21 del total de las 27 citas pertenecen a sus columnas de opinión.

\subsubsection{Sexismo}

Este código indexa la intención de menospreciar la preparación, la capacidad o el trabajo de Manuela Carmena, en contraposición siempre de una figura masculina. También engloba la aplicación estereotipos sexistas a su figura al hablar de su ropa o complementos (Lledó, 2013, p.44), puesto que no hay que perder de vista que a la mujer profesional se le presuponen unas expectativas y necesidades diferentes a las de los hombres (García Cuesta, 2009).

Se han hallado un total de 72 citas, de las que 13 están en textos informativos y 59 en textos de opinión. La mayoría de textos informativos recuerda que la alcaldesa le debe todo al PSOE, que la apoyó en su investidura. En este sentido, el sexismo es sustancialmente mayor en la primera semana de mandato que en el resto de las semanas (coincidiendo con su investidura y, por tanto, con más menciones a ese apoyo de Carmona). También en la sexta semana, por su encuentro con el Rey (al que acudió con un bolso considerado inadecuado) y por la puesta en marcha de la web Versión Original (dicen que la mantiene abierta Pablo Iglesias pero Carmena se compromete a suavizarla porque se lo pide Carmona).

Hay un total de tres citas sexistas que no hablan directamente de Carmena, pero que están en textos donde se la menciona ${ }^{20}$. Estas se han incluido por constituir un ejemplo de la tendencia a cosificar, sexualizar o menospreciar lo femenino de $A B C$.

Por otro lado, es muy común que se la compare en los textos de opinión con el exalcalde Tierno Galván: "la entrañable feminización de Tierno, con su Bonometro"; "Carmena es la repetición de la tragedia de Tierno"; "la partidocracia (no la democracia) llevó a la alcaldía a Tierno; a Manuela, también. Tierno hacía mofa de sus promesas; Manuela también"; "entre sus concejales parece la típica abuelita que se cuela en el guateque para hacerse la guay. Como Tierno cuando decía "al loro" o miraba la teta de Susana Estrada". 0 como una marioneta que está supeditada o a las órdenes de Pablo Iglesias.

Carmena, según las citas recogidas en artículos, ha resultado ser "una mantenida" de Carmona que no limpia su casa; es solo "una coartada estética - la entrañaba feminización de Tierno" porque "no tiene fuerza personal para purgar" su grupo de gobierno; también se

\footnotetext{
${ }^{20}$ En concreto, estas tres citas se refieren a la elección del alcalde de Cádiz: “Su pareja es la elección de la lideresa de Podemos en Andalucía, Teresa Rodríguez. Las chirigotas ya les han puesto mote en común: Los Clinton", en Expósito, A. (14 de junio de 2015). ¿Cómo lo explicará el PSOE? ABC, pp. 6-7 ; la segunda, a una intervención de Rita Maestre en un Pleno: "Llevaba un vestidito blanco como de Billie Jean King del que se le escapaba un tirante rojo del sujetador", en Belmonte, R. (23 de julio de 2015). Sorpresa y desazón. $A B C$, 59, y la tercera es una afirmación general: "Si Madrid era como Baden-Baden, había dos cosas que -según Valdivia- gustaban sobremanera a los madrileños: "los toreros valientes y las mujeres gordas", en Martínez, A. (17 de agosto de 2015). Esto ya no es Baden-Baden. ABC, 72. Las tres citas están en artículos de opinión firmados por diferentes personas.
} 
Figura 7. Citas codificadas como "sexismo" referentes a Manuela Carmena en el ABC. Elaboración propia.

\section{Sexismo relacionado con Carmena en $A B C$ (año 2015)}

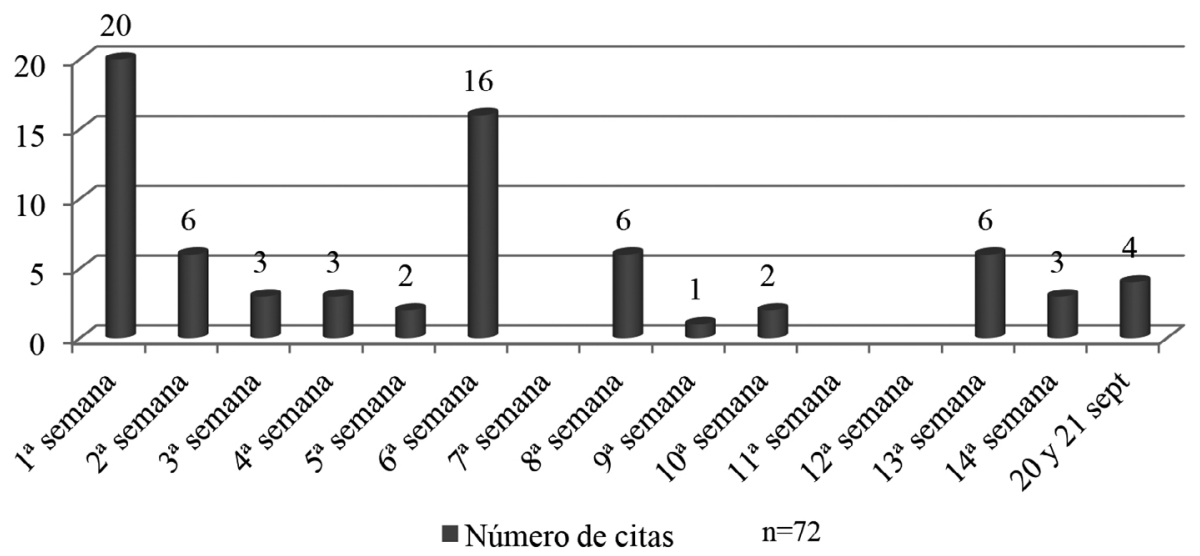

dice que los podemitas la usan "como la plastilina los niños"; es "alcaldesa de rebote por una felonía de Sánchez" y, por tanto, "carece de cualidades para gestionar la alcaldía de Madrid”; "Carmena es el hada del cuento de Podemos, pero no se la ve muy preocupada por sus incumplimientos de palabra", y tiene ideas propias "del misionero de una aldea de Zimbabue".

\subsubsection{Venezuela}

Este código se utiliza para indexar todas aquellas menciones que asimilan el partido o grupo de gobierno de Carmena con el régimen político venezolano. Son un total de 22 citas, divididas en 12 en información y 10 en opinión. Aunque no son muy numerosas, este goteo contribuye a forjar una imagen del equipo de gobierno, con Carmena a su cabeza, muy cercano al régimen chavista o que no simpatiza con los opositores a este régimen, algunos de ellos encarcelados. Así, aunque Carmena recibe a la mujer del alcalde de Caracas (que estaba encarcelado en ese momento), se la critica que no se haya querido hacer una foto con ella.

Especial mención merece el uso torticero del apellido Capriles en relación con un inmueble ocupado por el colectivo Patio de las Maravillas. Aunque se identifican como primos, solo en el último párrafo de una noticia de dos páginas se aclara que son primos muy lejanos y que el primo Capriles forma parte de un fondo de inversión (del que se desconoce su composición): ${ }^{21}$

21 "Por otro lado, fuentes empresariales precisan que «nada tiene que ver esta parte de la familia con Hernández Capriles», el político opositor a Nicolás Maduro y gobernador del estado de Miranda. «Miguel Ángel Capriles López -quien capitanea las inversiones en España- y Henrique Capriles Radonski son primos muy lejanos, de tercera o cuarta generación: el bisabuelo de uno era hermano del tatarabuelo del otro. Se conocen, porque uno es un importante empresario y el otro un importante político venezolano, pero no hay vinculación financiera ninguna»", en Chicote, J. (16 de junio de 2015). Errejón acudió el jueves a la ocupación del edificio de los Capriles en Madrid. ABC, pp.20-21. 
Por otro lado, fuentes empresariales precisan que "nada tiene que ver esta parte de la familia con Henrique Capriles, el político opositor a Nicolás Maduro y gobernador del estado de Miranda.

"Miguel Ángel Capriles López -quien capitanea las inveriones en España- y Henrique Capriles Radonski son primos muy lejanos, de tercera o cuarta generación: el bisabuelo de una era hermano del tatarabuelo del otro. Se conocen, porque uno es un importante empresario y el otro un importante político venezolano, pero no hay vinculación financiera ninguna".

Esta aclaración no se repite en posteriores textos, por lo que se sigue mencionando a este Capriles como familiar cercano del homónimo encarcelado en Venezuela.

\subsection{Caracterización negativa de Carmena}

En términos generales, Manuela Carmena mantiene una caracterización negativa en los textos publicados en el $A B C$ durante sus primeros 100 días de mandato. Dicho retrato está marcado por las relaciones establecidas entre once de los códigos que se han analizado. Todos ellos tienen en común que pertenecen a la categoría de aspectos semánticos y que han sido profusamente utilizados en los textos analizados, con la intención de desgastar la figura de Manuela Carmena.

Figura 8. Atributos o códigos que caracterizan negativamente a Manuela Carmena en el ABC. Elaboración propia.

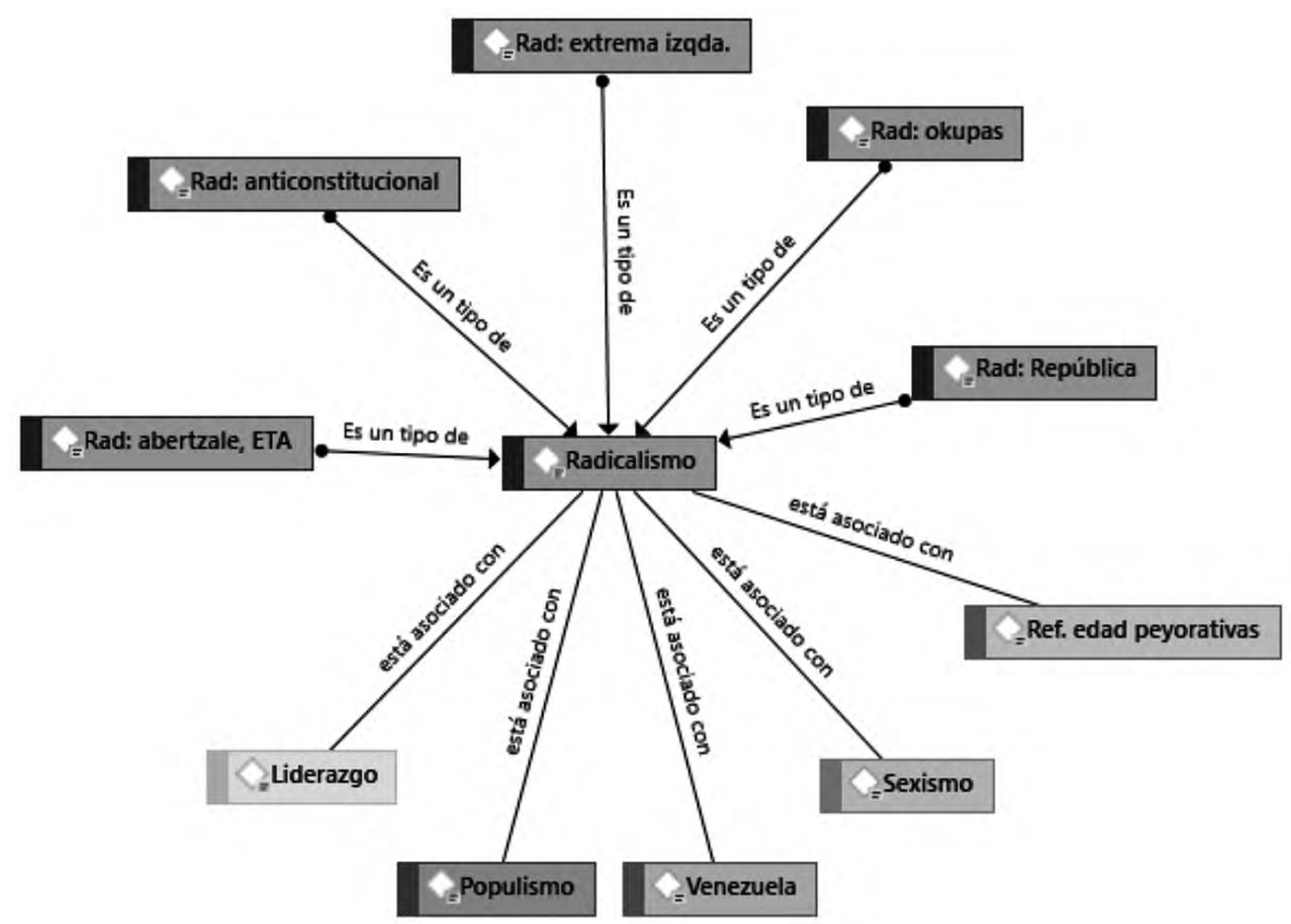




\section{Conclusiones}

El análisis del retrato de la figura de Manuela Carmena como alcaldesa de Madrid durante sus primeros cien días de mandato en el periódico $A B C$ puede calificarse como sesgado, peyorativo y sexista. $A B C$ retrató a Carmena como radical y la enmarcó en un movimiento político de tintes populistas, todo ello antes de que tuviera tiempo de iniciar alguna medida de calado en el municipio, dado que el mayor número de citas de estos códigos se encuentra en las primeras semanas de mandato.

La constancia y repetición de los ataques y la carencia casi absoluta de puntos de vista contrarios o discordantes (a través de artículos de opinión, por ejemplo, que sostuvieran una duda razonable sobre algún punto) inciden en la caracterización profesional de una Carmena errática, poco preparada, radical y dominada por Pablo Iglesias.

Es paradigmático el uso que se realizó de su condición de exjueza en los artículos de opinión, enfrentando siempre este atributo con el de falta de preparación o ideas descabelladas, constituyendo un claro ejemplo de violencia política hacia Manuela Carmena. La ironía y el cinismo son los recursos lingüísticos que se utilizan para coadyuvar a esta visión negativa de la alcaldesa, en lo que, por otro lado, no parece un caso aislado en el tratamiento de $A B C$ hacia las políticas progresistas o de partidos pertenecientes al espectro político de la izquierda ${ }^{22}$.

Al mismo tiempo que se incide y se ahonda en aspectos o acciones negativas de su mandato, como la falta de coordinación entre los miembros del gobierno, su relación con hechos ajenos a su responsabilidad como el auge de las ocupaciones en 2008, y se hace referencia a su militancia en el partido Comunista en su juventud; se obvia de forma clara uno de los hitos de su vida: que fue fundadora del despacho laboralista de Atocha, que fue objeto de un atentado de extrema derecha en 1977 en el que murieron cinco personas. De esta forma, el encuadre que se realiza de Carmena enfatiza, llegando a deformar en algunos casos como el mencionado de Capriles, todo lo negativo de sus primeros cien días de mandato, y silencia o minimiza cualquier aspecto que pudiera despertar empatía en el lector, con la intención última de desgastar su figura y minar su popularidad.

Como fémina, a Carmena se la retrata como demasiado mayor para el cargo y se la critica que no vista acorde a los cánones de la moda o del protocolo, reforzando así los estereotipos de belleza, que exigen a las mujeres, no solo ser buenas profesionales, sino permanecer bellas a lo largo del tiempo. El sexismo aparece como consustancial a los articulistas de $A B C$, que aún son capaces de hablar de las mujeres como si fueran un producto para el disfrute o consumo masculino. Alguno de los comentarios sexistas indexado se ha hecho incluso por parte de una articulista, en lo que representa un proceso de aculturación de esta periodista hacia el modelo masculino dominante en el rotativo (Ruiloba, 2013; García de León, 1994).

\footnotetext{
${ }^{22}$ Cristina Alberdi (Méndez, 2002, pp.157-158) explica que en su época como ministra se publicó una doble página "en la que se criticaba algunas subvenciones concedidas por el Ministerio a asociaciones de muy diversa índole, algunas de ellas ridiculizadas por sus nombres y la labor que desarrollaban, [...] que reforzaban un mensaje muy reiterado por el $A B C$ : el Ministerio de Asuntos Sociales tira el dinero público".
} 
Todos estas caracterizaciones y atributos negativos en algunas ocasiones han emergido como críticas legítimas de los primeros errores cometidos por el equipo de gobierno municipal encabezado por Manuela Carmena, pero en otras se han forzado, creando relaciones dialécticas de causalidad inexistentes o llegando incluso a obviar información relevante para la comprensión completa del acontecimiento noticioso. Los textos de $A B C$ refuerzan, de esta forma, los estereotipos de género; sesgan las informaciones y tratan de influir en la opinión pública mediante este retrato deformado de una mujer que, objetivamente, tiene suficiente preparación académica y experiencia en gestión para un cargo de estas características.

Otra de las conclusiones a las que llegamos en esta investigación es la comparación constante que existe entre la figura de Manuela Carmena y otras figuras masculinas, como otro ángulo desde el que se aborda el descrédito de su persona a través de un uso sexista de estos falsos paralelismos. El hecho, además, de que se le prive en numerosas ocasiones de hablar con su voz a través del estilo directo en la narración, contribuye al retrato de una persona que carece de las mínimas aptitudes oratorias requeridas para el cargo; al tiempo que se hace hincapié en que, cuando habla, lo hace sin pensar primero lo que va a decir.

La conclusión operativa de este análisis crítico es que la praxis y rutinas profesionales del $A B C$ deben ser revisadas y corregidas, dado que un periódico, en un país democrático, ha de tener entre sus objetivos informar a la población de hechos (no opiniones) relevantes, para que esta pueda forjarse sus propios juicios sobre los acontecimientos, en lugar de mezclar opinión e información, contraviniendo, de esta forma, los límites deontológicos de la profesión periodística.

\section{Bibliografía}

ASOCIACIÓN “MUJERES EN LA TRANSICIÓN DEMOCRÁTICA”. (1999). Españolas en la Transición. De excluidas a protagonistas (1973-1982). Madrid: Biblioteca Nueva.

BLAS, I. (1999). Comunicación e información de mujeres para mujeres. En Españolas en la Transición. De excluidas a protagonistas (1973-1982) (pp: 325-426). Madrid: Biblioteca Nueva.

BORDIEU, P. (2015). La dominación masculina. Madrid: editorial Anagrama, colección Argumentos [edición original en 2000: La domination masculine].

BENGOECHEA, M. (2015). Lengua y género. Madrid: editorial Síntesis.

CARMENA, M. (2014). Por qué las cosas pueden ser diferentes. Reflexiones de una jueza. Madrid: clave intelectual.

CHISHOLM-BURNS, M.A, SPIVEY, C.A, HAGEMANN, T. \& JOSEPHSON, M.A. (2017). Women in leadership and the bewildering glass ceiling. Am J Health-Syst Pharm, 74 (5), 312-324.

D'ADAMO, 0., GARCÍA BEAUDEOUX, V. \& FREIDENBERG, F. (2007). Medios de comunicación y opinión pública. Madrid: McGrawHill.

DE BEAVOIR, S. (1949). El segundo sexo. Madrid: Ediciones Cátedra, colección Feminismos.

EAGLY, A. \& HEILMAN, M.E. (2016). Gender and leadership: introduction to the special issue. The Leadership Quarterly, 27, 349-353. 
ESPÍ-HERNÁNDEZ, A. (2017). Presencia de la mujer y brecha de género en la política local española. Femeris, 2 (1), 133-147. Doi: https://doi.org/10.20318/femeris. 2017. 3556

GARCÍA CUESTA, S. (2009). La abogacía en Santa Cruz de Tenerife: una perspectiva de género. Revista Altántida: revista canaria de Ciencias Sociales, 1, 65-92.

GARCÍA DE LEÓN, M.A. (1994). Élites discriminadas: sobre el poder de las mujeres. Bogotá: editorial Arthropos.

GÓMEZ-FERRER MORANT, G. \& DEL MORAL VARGAS, M. (2015). Las pioneras de la gestión local: concejalas y alcaldesas designadas durante la dictadura de Primo de Rivera y el Gobierno de Berenguer (1924-1930). En Nielfa, Gloria (coord.): Mujeres en los Gobiernos locales. Alcaldesas y concejalas en la España contemporánea (pp.: 41-72). Madrid: Biblioteca nueva.

INSTITUTO DE LA MUJER Y PARA LA IGUALDAD DE OPORTUNIDADES (2015). Mujeres en cifras -Poder y toma de decisiones- Administración local. Recuperado de http:// www.inmujer.gob.es/MujerCifras/PoderDecisiones/AdmonLocal.htm

LIPPMANN, W. (2003). La opinión pública. Madrid: inActuales Langre. [Edición original de 1922, Public Opinion].

LLEDÓ CUNILL, E. (2012). Cambio lingüístico y prensa. Problemas, recursos y perspectivas. Barcelona: Laertes ediciones.

MATEOS, R. (2017). Mujeres y liderazgo empresarial: explorando la brecha de género en la cima. Femeris, 2 (2), 53-80. doi: https://doi.org/10.20318/femeris.2017.3758

MCQUAIL, D. (1985). Introducción a la teoría de la comunicación de masas. Barcelona: Paidós Comunicación.

MELDENBERG, T. \& KARPOWITZ, C.F. (2016). Women's authority in political decision-making groups. The Leadership Quarterly, 27, 487-503.

MÉNDEZ, L. (ED.). (2001). Cristina Alberdi. El poder es cosa de hombres. Madrid: La esfera de libros.

MILLS, S. \& MULLANY, L. (2011). Language, gender and feminism. Routledge, Nueva York. MORENO, A., ROVETTO, F. \& BUITRAGO, A. (2007). ¿De quién hablan las noticias? Barcelona: editorial Icaria.

NIELFA, G. (2015). Mujeres en los Gobiernos locales. Alcaldesas y concejalas en la España contemporánea. Madrid: Biblioteca nueva.

O'BRIEN, DIANA Z. \& RICKNE, J. (2016). Gender quotas and women's political leadership. American Political Science Review. Vol, 110 (1), 112-126.

PLAZA, JUAN F. \& DELGADO, C. (eds.) (2007). Género y comunicación. Caracas: editorial Fundamentos.

RYAN, M. K., HASLAM, S. ALEXANDER, M., THEKLA, R., FLOOR, S., JANKA \& PETERS, K. (2016). Getting on top of the glass cliff: Reviewing a decade of evidence, explanations, and impact. The Leadership Quarterly. 27, 446-455.

RIDGEWEY, C. L. (2001). Gender, status \& Leadership. Journal of Social Issues, 57 (4), 637-655. RODRÍGUEZ MOYA, J. \& GAGO GARCÍA, C. (2015). El periodo democrático: la progresiva incorporación de las mujeres a los gobiernos a partir de 1975. En Nielfa, Gloria 
(coord.) Mujeres en los Gobiernos locales. Alcaldesas y concejalas en la España contemporánea (pp.: 181-220). Madrid: Biblioteca nueva.

RUILOBA, J. M. (2013): “Liderazgo político y género en el siglo XXI”, Entramados, 9 (1), pp.142-155.

SALAS, M. \& COMABELLA, M. (1999). Asociaciones de mujeres y movimiento feministas. En Españolas en la Transición. De excluidas a protagonistas (1973-1982) (pp: 25126). Madrid: Biblioteca Nueva.

SCHEIN, VIRGINIA E., MUELLER, R., LITUCHY, T. \& LIU, J. (1996). Think manager-think male: A global phenomenon? Journal of Organizational Behavior, 17, 33-41.

SCZESNY, S. (2003). A Closer Look Beneath the Surface: Various Facets of the Think- Manager -Think-Male Stereotype. Sex Roles, 49 (7), 353-363.

SORIANO, S. (2020). Violencia y acoso en el ámbito político como forma específica de violencia contra las mujeres. Femeris, 4 (3), 134-157. doi: https://doi.org/10.20318/ femeris. 2019. 4933

STRAUSS, A. \& CORBIN, J. (2002). Bases de la investigación cualitativa. Técnicas y procedimientos para desarrollar la teoría fundamentada. Medellín: editorial Universidad de Antioquía.

TORRES, M. (2015). Manuela Carmena en el diván de Maruja Torres. Barcelona: Planeta.

TRINIDAD, A., CARRERO, V. \& SORIANO, R. M. (2006). Teoría fundamentada "Grounded Theory", La construcción de la teoría a través del análisis interpretacional. Colección Cuadernos Metodológicos n³7. Madrid: Centro de Investigaciones Sociológicas.

VALCÁRCEL, A. (2012). La política de las mujeres. Madrid: ediciones Cátedra, colección Feminismos [primera edición en 1997].

VIGARA, A. M. ${ }^{\text {a }}$ (2001) Libro de estilo de ABC, Madrid: Ariel.

WOLF, N. (2002). The beauty myth. New York: Harper Perennial. 